\title{
SITTING VERSUS LATERAL POSITION FOR INDUCTION OF SPINAL ANESTHESIA IN ELDERLY PATIENTS: A RANDOMIZED CONTROLLED TRIAL
}

\author{
SHOWKAT AHMAD BHAT ${ }^{1}$, SHOWKAT HUSSAIN TALI ${ }^{2 *}$, KUMAR NM ${ }^{3}$, SHAGUFTA YOUSUF ${ }^{4}$
}

${ }^{1}$ Department of Anesthesiology, Southern Railways Headquarter Hospital, Perambur, Ayanavrum, Chennai, Tamil Nadu, India. ${ }^{2}$ Consultant Paediatrics, Department of Health and medical Education, Jammu and Kashmir, India. ${ }^{3}$ Department of Anesthesiology, Southern Railways Headquarter Hospital, Perambur, Ayanavrum, Chennai, Tamil Nadu, India. ${ }^{4}$ Department of Gynaecology and Obstetrics, SKIMS, Srinagar, Jammu and Kashmir, India. Email: drshowkatshifa@gmail.com

Received: 04 October 2016, Revised and Accepted: 24 October 2016

\section{ABSTRACT}

Objectives: To compare the effect of induction position (sitting versus lateral) for spinal anaesthesia in the elderly patient on hemodynamic, sensory block and motor block characteristics and patient satisfaction.

Material and methods: Randomized controlled trial of patients undergoing spinal anaesthesia for lower abdominal, pelvic, lower limb and urological surgeries aged more than 60 years. Hyperbaric Bupivacain $(0.05 \%)$ was injected into the spinal space while the patients were either in sitting or lateral position. Effects on hemodynamic parameters, sensory block and motor block characteristics and patient satisfaction were analysed.

Results: Induction position for spinal anaesthesia does not affect the hemodynamic parameters and incidence of adverse effects when adequate preloading is done. There was no statistically significant difference in the sensory level and motor level achieved. However lateral position appears to be more comfortable for elderly patients $(\mathrm{P}=0.03)$.

Conclusions: Induction position for administration of spinal anaesthesia has no effect on hemodynamic parameters or block characteristics except that patients feel more comfortable in lateral position.

Keywords: Spinal anesthesia, Induction position, Hyperbaric bupivacaine.

(C) 2017 The Authors. Published by Innovare Academic Sciences Pvt Ltd. This is an open access article under the CC BY license (http://creativecommons. org/licenses/by/4. 0/) DOI: http://dx.doi.org/10.22159/ajpcr.2017.v10i2.15523

\section{INTRODUCTION}

Spinal anesthesia appears to be more beneficial in elderly patients for lower abdominal, lower limb, and urological surgeries as it avoids the problems associated with general anesthesia such as airway manipulation, polypharmacy, post-operative respiratory problems, and cognitive dysfunction $[1,2]$. It can be initiated with the patient in either the sitting or the lateral position, and each position has its advantages and disadvantages [3]. The sitting position appears to be optimal for the placement of spinal anesthesia as identification of landmarks is much easier. However, maintaining the sitting position is relatively more difficult and uncomfortable for premedicated elderly patients. The medical sympathectomy following spinal anesthesia with enhanced gravity-induced peripheral blood pooling, especially in the sitting position often results in significant hypotension [1]. In spite of increasing use of spinal anesthesia, the induction position has not been standardized. In elderly patients, influence of the positions on hemodynamic stability and block character (sensory and motor nerve) has not been studied extensively and the evidence that is available is conflicting [4-6]. In elderly patients, influence of the positions on hemodynamic stability and block character (sensory and motor nerve) has not been studied extensively. This study was designed to compare hemodynamic effects, block characteristics, and patient satisfaction level associated with sitting and lateral positions for initiating spinal anesthesia in the elderly patient. Our null hypothesis was that sitting position is not better than the lateral position for induction of spinal esthesia in elderly patients aged more than 60 years. Our alternate hypothesis was that lateral position is better than sitting position for induction spinal anesthesia in elderly patients aged more than 60 years.

\section{Aims and objectives}

To compare the effect of induction position (sitting vs. lateral) for spinal anesthesia in the elderly patient on hemodynamics, sensory block and motor block characteristics, and patient satisfaction.

\section{METHODS}

This randomized controlled trial was conducted between June 10, 2015 and June 09, 2016. Elderly patients aging more than 60 years undergoing lower abdominal, pelvic, lower limb, and urological surgeries were enrolled for the study. Approval from the Institute Ethics Committee was obtained, and a written informed consent was taken from the patients.

\section{Study design}

A randomized controlled clinical trial with parallel enrolment.

\section{Inclusion criteria}

Patients of both genders undergoing spinal anesthesia for lower abdominal, pelvic, lower limb, and urological surgeries aged more than 60 years, with American Society of Anesthesiologists 1 (ASA 1) and ASA 2 physical status, having height between 1.4 and $1.8 \mathrm{~m}$ and with weight $<80$ kgs.

\section{Exclusion criteria}

Patient's refusal to give consent, the patients with infection at the site of injection, coagulopathy or bleeding diathesis, increased intracranial tension, preexisting neurological deficits, and hemodynamic instability. 
Sample size

The sample size was calculated using the formula for the hypothesis of 2-parallel sample means. For sample size determination, the ranges of time of highest sensory block (T10) in each group were considered as 5.5 and 6, and standard deviations (range/4) came out to be 1.4 and 1.5 , respectively. Accordingly, 35 patients in each group achieved $80 \%$ power to detect a mean difference of 1 with $5 \%$ level of significance. To account for attrition, a total of 50 patients were selected in each group.

\section{Randomization}

Before entry to operation theater patients were randomized either to sitting position group or lateral position group through the predetermined randomization code generated through computerized software.

\section{Concealment}

The group allocation was concealed in consecutively numbered, sealed opaque envelopes.

A detailed history was taken and a thorough systemic and general examination was carried out. Spine was examined thoroughly. Investigations, such as complete blood count, electrocardiogram, and chest radiograph, were obtained and analyzed. The procedure to be performed was explained to the patient and a written informed consent was obtained. On the day of surgery, nothing by mouth status was confirmed. Investigations were rechecked for any abnormality and informed consent was also rechecked for completeness. General anesthesia trolley, spinal anesthesia trolley, and resuscitation drugs were prepared under supervision and checked. In the operation theater, the patient was attached to multichannel monitor for monitoring of electrocardiography, pulse oximetry, and noninvasive blood pressure (BP) monitoring. Baseline heart rate, $\mathrm{SPO}_{2}$, and $\mathrm{BP}$ were recorded. A large-bore intravenous (IV) cannula was inserted and secured on the dorsum of nondominant hand. The patient was preloaded with $10 \mathrm{ml} / \mathrm{kg}$ of IV lactated Ringer's solution. The patient was given position for spinal anesthesia. The position of spinal anesthesia was decided as per randomization code. For sitting position, the patients were sitting with feet resting on stool, hugging a pillow, and back facing toward the anesthesiologist. For lateral position, the patients were lying in lateral position on the operating table with the knees and hips in flexion. Spinal anesthesia was performed with the patient either in sitting or lateral position at L3-L4 or L4-L5 level via midline approach using a 25 gauge Quincke's spinal needle. Hyperbaric bupivacaine $(0.5 \%)$ was injected with the bevel of the needle facing cephalad after clear and free flow of cerebrospinal fluid and after confirming negative aspiration for blood at the speed of $0.5 \mathrm{ml} / \mathrm{seconds}$. The volume of bupivacaine was $3 \mathrm{ml}$ in patients $<160 \mathrm{~cm}$ in height and $3.5 \mathrm{ml}$ in patients $>160 \mathrm{~cm}$. Immediately after withdrawing the spinal needle, the patients was placed in supine position. Initially, after 2 minutes and 5 minutes and afterward after every 5 minutes after the injection of drug until 30 minutes, assessments was made for height of sensory and motor blocks, heart rate, systolic and diastolic BPs. Sensory level assessment was done with pinprick in midline. Motor assessment was done with 0-3 point scale $(0=$ full extension of knees and feet, $1=$ just able to move knees and feet, $2=$ able to move feet only, and $3=$ unable to move feet and knees). A decrease in mean arterial BP of $>20 \%$ of the baseline level was treated with fluid boluses followed by incremental doses of IV ephedrine $5 \mathrm{mg}$ when needed. A decrease in the heart rate $>20 \%$ of the baseline level was treated with $0.6 \mathrm{mg}$ atropine intravenously. At the end of surgery, the patients were asked about their satisfaction for overall comfort level for position during spinal anesthesia in terms of three point scale $(0=$ Not comfortable, 1 =Comfortable, and 2=Very comfortable).

\section{OBSERVATIONS, RESULTS AND ANALYSIS}

Number of patients assessed for eligibility and finally analyzed is depicted in CONSORT flow diagram (Fig. 1). Baseline characteristics of the patients are depicted in Table 1. Hemodynamic effects are presented in Table 2. Sensory and motor block characteristics are in Tables 3 and 4, respectively. Side effect profile and patient comfort level has been shown in Table 5 .

\section{DISCUSSION}

In our study, a total of 100 patients were enrolled and finally analyzed. Each group consisted of 50 patients who were comparable in age, sex, weight, height, ASA grade, and baseline hemodynamic parameters (Fig. 1 and Table 2). We observed that induction position for spinal anesthesia does not affect the hemodynamic parameters and incidence of adverse effects when adequate preloading is performed (Tables 2 and 5). There was no statistically significant difference in the sensory level and motor level achieved (Tables 3 and 4). However, lateral position appears to be more comfortable for elderly patients (Table 5). The strength of our study is, that is a randomized controlled trial with parallel enrollment, adequate sample size and with no dropouts. The limitation of our study is that blinding was not performed. However, blinding was not possible because of the nature of the study. This limits its generalizability.

\section{Intraoperative hemodynamics}

In our study, during the entire observation period after induction of spinal anesthesia, there was no significant difference between the

Table 1: Baseline characteristics of patients

\begin{tabular}{|c|c|c|c|c|c|}
\hline Variables $^{\wedge}$ & Position & Mean/male (n) & SD/female (n) & IQR & $\mathbf{p}$ \\
\hline \multirow[t]{2}{*}{ Sex } & Sitting & $--/ 27$ & $--/ 23$ & & 0.45 \\
\hline & Lateral & $--/ 30$ & $--/ 20$ & & \\
\hline \multirow[t]{2}{*}{ Age (years) } & Sitting & 64.06 & 2.89 & 3.50 & 0.20 \\
\hline & Lateral & 66.08 & 3.28 & 3.90 & \\
\hline \multirow[t]{2}{*}{ Height (m) } & Sitting & 1.71 & 0.17 & 0.07 & 0.24 \\
\hline & Lateral & 1.72 & 0.17 & 0.09 & \\
\hline \multirow[t]{2}{*}{ Weight (kg) } & Sitting & 71.74 & 6.00 & 16.00 & 0.22 \\
\hline & Lateral & 68.02 & 8.16 & 11.21 & \\
\hline \multirow[t]{2}{*}{ BMI } & Sitting & 22.17 & 4.44 & 4.41 & 0.29 \\
\hline & Lateral & 24.05 & 2.88 & 4.23 & \\
\hline \multirow[t]{2}{*}{$\mathrm{ASA}^{\#}$} & Sitting & 1.37 & 0.49 & 1.10 & 0.28 \\
\hline & Lateral & 1.34 & 0.39 & 0.85 & \\
\hline \multirow[t]{2}{*}{ Baseline heart rate $^{\wedge}$} & Sitting & 80.70 & 8.46 & 8.25 & 0.08 \\
\hline & Lateral & 79.02 & 11.58 & 21.50 & \\
\hline \multirow[t]{2}{*}{ Baseline systolic $\mathrm{BP}^{\wedge}$} & Sitting & 127.51 & 7.31 & 9.25 & 0.86 \\
\hline & Lateral & 124.80 & 5.11 & 5 & \\
\hline \multirow{2}{*}{ Baseline diastolic $\mathrm{BP}^{\wedge}$} & Sitting & 85.20 & 4.37 & 5.25 & 0.4 \\
\hline & Lateral & 83.61 & 4.79 & 9 & \\
\hline
\end{tabular}

^All variables failed “Normality” test. Hence Mann-Whitney test applied. "Ordinal data. Hence Mann-Whitney test applied. BP: Blood pressure, BMI: Body mass index ASA: American Society of Anesthesiologists, SD: Standard deviation, IQR: Interquartile range 


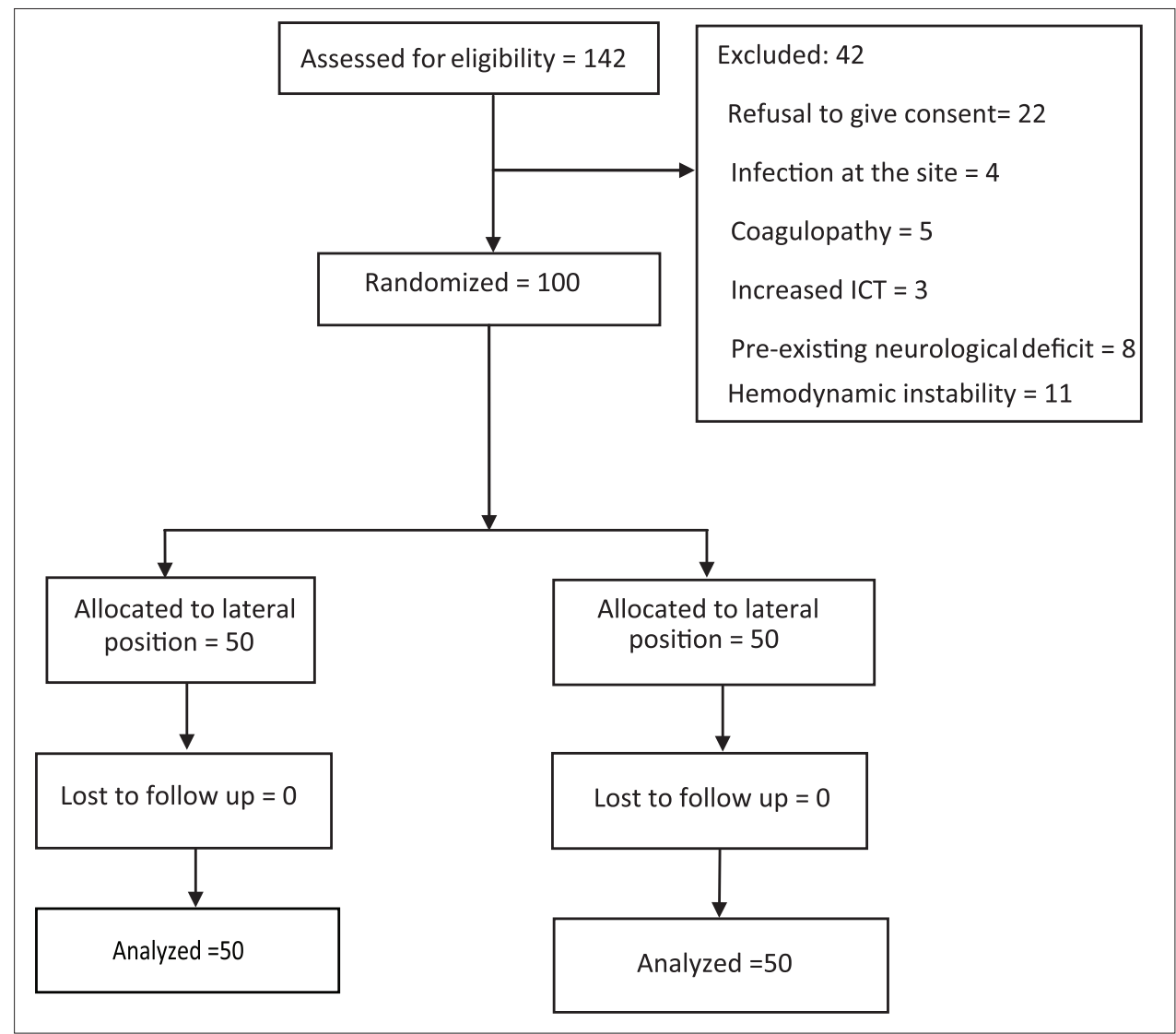

Fig. 1: CONSORT flow diagram

Table 2: Effect of induction position on hemodynamic parameters

\begin{tabular}{|c|c|c|c|c|c|c|c|c|c|}
\hline \multirow[t]{2}{*}{ Variable } & \multirow[t]{2}{*}{ Position } & \multicolumn{8}{|c|}{ Heart rate/systolic BP/diastolic BP } \\
\hline & & Baseline & $2 \mathrm{~m}$ & $5 \mathrm{~m}$ & $10 \mathrm{~m}$ & $15 \mathrm{~m}$ & $20 \mathrm{~m}$ & $25 \mathrm{~m}$ & $30 \mathrm{~m}$ \\
\hline \multirow[t]{2}{*}{ Mean } & Sitting & $\begin{array}{l}82.7 / 124.6 / \\
77.2\end{array}$ & $\begin{array}{l}89.1 / 120.8 / \\
77.8\end{array}$ & $\begin{array}{l}71.2 / 116.2 / \\
76.2\end{array}$ & $\begin{array}{l}72.8 / 110.2 / \\
69.9\end{array}$ & $\begin{array}{l}74.0 / 114.9 / \\
67.2\end{array}$ & $\begin{array}{l}66.1 / 104.9 / \\
66.2\end{array}$ & $\begin{array}{l}69.5 / 103.8 / \\
66.6\end{array}$ & $\begin{array}{l}67.5 / 109.5 / \\
66.9\end{array}$ \\
\hline & Lateral & $\begin{array}{l}82.5 / 122.9 / \\
74.6\end{array}$ & $\begin{array}{l}85.6 / 122.6 / \\
78.4\end{array}$ & $\begin{array}{l}71.8 / 113.2 / \\
73.2\end{array}$ & $\begin{array}{l}67.6 / 120.0 / \\
70.5\end{array}$ & $\begin{array}{l}67.2 / 116.0 / \\
68.9\end{array}$ & $\begin{array}{l}65.7 / 113.9 / \\
67.0\end{array}$ & $\begin{array}{l}64.3 / 104.9 / \\
64.7\end{array}$ & $\begin{array}{l}65.1 / 114.6 / \\
66.7\end{array}$ \\
\hline Standard & Sitting & $8.5 / 5.1 / 4.4$ & $8.5 / 5.5 / 4.8$ & $7.2 / 6.4 / 4.7$ & $7.1 / 6.8 / 4.8$ & $8.4 / 6.2 / 4.5$ & 7.6/7.1/5.1 & $8.6 / 5.1 / 4.3$ & $8.5 / 4.9 / 3.9$ \\
\hline & Lateral & $11.6 / 7.3 / 4.8$ & $10.6 / 6.64 / 4.9$ & $8.3 / 6.4 / 5.4$ & $8.9 / 7.2 / 5.5$ & $8.7 / 7.0 / 5.6$ & $6.5 / 6.3 / 5.5$ & $6.3 / 6.1 / 4.8$ & $6.3 / 94.4 / 3.8$ \\
\hline $\mathrm{p}$ value & & $\begin{array}{l}0.79 / 0.90 / \\
0.40\end{array}$ & $\begin{array}{l}0.22 / 0.22 / \\
0.60\end{array}$ & $\begin{array}{l}0.34 / 0.22 / \\
0.26\end{array}$ & $\begin{array}{l}0.30 / 0.21 / \\
0.47\end{array}$ & $\begin{array}{l}0.15 / 0.42 / \\
0.13\end{array}$ & $\begin{array}{l}0.13 / 0.41 / \\
0.58\end{array}$ & $\begin{array}{l}0.20 / 0.56 / \\
0.40\end{array}$ & $\begin{array}{l}0.55 / 0.07 / \\
0.40\end{array}$ \\
\hline
\end{tabular}

${ }^{\wedge}$ Data failed "Normality" test. Hence Mann-Whitney test applied. BP: Blood pressure

Table 3: Effect of induction position on sensory block characteristics

\begin{tabular}{|c|c|c|c|c|}
\hline \multirow{2}{*}{$\begin{array}{l}\text { Time since } \\
\text { induction }\end{array}$} & \multicolumn{4}{|c|}{ Number of patients in sitting/lateral position } \\
\hline & 5 minutes & 10 minutes & 20 minutes & 30 minutes \\
\hline \multicolumn{5}{|l|}{ Sensory level } \\
\hline T6 & & & $12 / 13$ & $13 / 14$ \\
\hline $\mathrm{T} 7$ & & & $3 / 4$ & $3 / 4$ \\
\hline T8 & & $5 / 8$ & $23 / 21$ & $24 / 23$ \\
\hline $\mathrm{T} 10$ & $2 / 3$ & $26 / 27$ & $12 / 11$ & $10 / 09$ \\
\hline $\mathrm{T} 12$ & $24 / 27$ & $19 / 15$ & & \\
\hline L1 & $24 / 20$ & & & \\
\hline $\mathrm{p}$ & 0.40 & 0.12 & 0.92 & 0.91 \\
\hline
\end{tabular}

Pearson Chi-square test applied

mean heart rate of patients in sitting and lateral position groups; between the mean systolic BP of patients in sitting and lateral position groups and between the mean diastolic BP of patients in sitting and lateral position groups (Table 2). Shahzad and Afshan [6] also reported similar findings. Obasuyi et al. [7] in their study concluded that the changes in hemodynamic variables were significantly lower in the group in lateral versus sitting position in patients undergoing spinal anesthesia with bupivacaine for vascular surgery of the lower limb. This can be explained by the fact that unlike our study, in the above study, preloading was not performed and the level of injection of bupivacaine was much higher (T10) as compared to ours (L34 or L4-5).

\section{Sensory level}

In our study, we found that the onset of anesthesia was relatively faster in lateral group and they achieved higher sensory level at 5 minutes and at $10^{\text {th }}$ minute and onward as well. Maximum sensory level achieved was T6 in both groups. After 30 minutes, $28 \%$ patients who were given lateral position achieved T6 level as compared to $26 \%$ in sitting group. However, these differences were statistically not significant 
Table 4: Effect of induction position on motor block characteristics

\begin{tabular}{|c|c|c|c|c|c|c|c|c|}
\hline $\begin{array}{l}\text { Time since } \\
\text { induction }\end{array}$ & 2 minutes & 5 minutes & 10 minutes & 15 minutes & 20 minutes & 25 minutes & 30 minutes & $p$ value \\
\hline $\begin{array}{l}\text { Sitting/lateral } \\
\text { position }\end{array}$ & & & & & & & & 0.40 \\
\hline Motor level 2 & $10 / 14$ & $0 / 0$ & $0 / 0$ & $0 / 0$ & $0 / 0$ & $0 / 0$ & $0 / 0$ & \\
\hline Motor level 3 & $40 / 36$ & $50 / 50$ & $50 / 50$ & $50 / 50$ & $50 / 50$ & $50 / 50$ & $50 / 50$ & \\
\hline
\end{tabular}

Pearson Chi-square test applied

Table 5: Need for medications and patient comfort score

\begin{tabular}{llll}
\hline $\begin{array}{lll}\text { Medication required/patient } \\
\text { comfort score }(\mathbf{0 , 1}, \mathbf{2})\end{array}$ & Position & \multirow{2}{*}{ p value } \\
\cline { 2 - 3 } & Sitting & Lateral & \\
\hline Atropine/ephedrine/nil & $5 / 4 / 41$ & $4 / 8 / 38$ & 0.7 \\
Score 0/1/2 & $15 / 21 / 14$ & $1 / 2 / 47$ & 0.03 \\
\hline
\end{tabular}

Pearson Chi-square test applied

(Table 3). Laithangbam et al. [8] reported similar findings. Shahzad and Afshan [6] observed that the onset of sensory block in the sitting group was 4.5 minutes compared with 5.4 minutes in the lateral group $(p<0.006)$. Since we have used hyperbaric bupivacaine, it is more likely that the drug settled down more quickly in sitting position than in lateral position. Hence, we got faster onset of anesthesia and higher sensory level in lateral position group.

\section{Motor level}

In our study, we found that after 2 minutes, $22 \%$ of patients who were given lateral position had motor level score of 2, 78\% patients had motor level score of 3 while $30 \%$ patients who were given lateral position had motor level score of 2 and $70 \%$ had motor level score of 3 . This shows onset of motor blockade was faster in lateral position group. However, this difference was statistically not significant (Table 4). From 5 minutes and onward, the patients in both the groups had motor level score of 3. Shahzad and Afshan [6] also observed that there was no difference between the groups for maximum density of motor block and mean time to achieve this. Laithangbam et al. [8] reported higher block in lateral position.

\section{Side effects}

In our study, we observed that in lateral position group, $76 \%$ patients did not have hypotension or bradycardia, and therefore, did not require any medication. $8 \%$ patients required atropine for bradycardia and $16 \%$ patients required ephedrine for hypotension. While in sitting position, $82 \%$ patients did not require any medication for hypotension and bradycardia while $10 \%$ patients required atropine and $8 \%$ required ephedrine. However, the difference was statistically not significant (Table 5). Fredman et al. [1] also concluded that the incidence of hypotension and hypotension-related adverse effects was similar when intrathecal anesthesia was induced in the sitting or lateral position. Shahzad and Afshan [6] in their study found that the incidence of side effects was similar in two groups. Laithanghbam et $a l$. [9] reported that chances of hypotension are more in lateral group. This may be due to the fact that they were evaluating pregnant women at cesarean section who are more prone to develop hypotension in lateral position.

\section{Patient comfort}

In our study, we found that there was a significant difference between the two positions with respect to the patient comfort score. $94 \%$ patients were having patient comfort score of 2 in lateral position as compared to $28 \%$ in sitting position. $4 \%$ patients were having patient comfort score of one in lateral position as compared to $42 \%$ in sitting position. Just two patients in lateral position were having patient comfort score of two as compared to $30 \%$ patients in sitting position (Table 5). Fredman et al. [1] found that there was no significant difference between sitting and lateral position in terms of patient comfort. Shahzad and Afshan [6] found that patients were more comfortable in lateral position than in sitting position. This finding was in conformity with our findings.

\section{CONCLUSION}

Induction position for spinal anesthesia does not affect the hemodynamic parameters and block characteristics. However, lateral position appears to be more comfortable for elderly patients.

\section{REFERENCES}

1. Fredman B, Zohar E, Rislick U, Sheffer O, Jedeikin R. Intrathecal anaesthesia for the elderly patient: The influence of the induction position on perioperative haemodynamic stability and patient comfort. Anaesth Intensive Care 2001;29(4):377-82.

2. Kelly JD, McCoy D, Rosenbaum SH, Brull SJ. Haemodynamic changes induced by hyperbaric bupivacaine during lateral decubitus or supine spinal anaesthesia. Eur J Anaesthesiol 2005;22(9):717-22.

3. Birnbach DJ, Browne IM. Anesthesia for obstetrics. In: Miller RD, editor. Anesthesia. $7^{\text {th }}$ ed. USA: Churchill Livingstone, An Imprint of Elsevier; 2009. p. 2203-40

4. Kalso E, Tuominen M, Rosenberg PH. Effect of posture and some c.s.f. characteristics on spinal anaesthesia with isobaric $0.5 \%$ bupivacaine. $\mathrm{Br}$ J Anaesth 1982;54(11):1179-84.

5. Kuusniemi KS, Pihlajamäki KK, Pitkänen MT, Helenius HY, Kirvelä OA. The use of bupivacaine and fentanyl for spinal anesthesia for urologic surgery. Anesth Analg 2000;91(6):1452-6.

6. Shahzad K, Afshan G. Induction position for spinal anaesthesia: Sitting versus lateral position. J Pak Med Assoc 2013;63(1):11-5.

7. Obasuyi BI, Fyneface-Ogan S, Mato CN. A comparison of the haemodynamic effects of lateral and sitting positions during induction of spinal anaesthesia for caesarean section. Int J Obstet Anesth 2013;22(2):124-8

8. Arokyamuthu V, Joseph EJ. A comparison of hemodynamic effects of lateral and sitting positions during induction of spinal anaesthesia for caesarean section. Global journal for research analysis 2016;5(4).

9. Laithangbam PK, Singh NR, Fanai RL, Singh SS, Shashank DS, Nayagam HA. Comparision of lateral, Oxford and sitting positions for combined spinal and epidural ansthesia for elective caesarean section. Journal of Medical Society 2013; 27(1): 70-4. DOI: 10.4103/09724958.116651. 